\title{
Restricted weekend service inappropriately delays discharge after acute myocardial infarction
}

\author{
A M Varnava, J E C Sedgwick, A Deaner, K Ranjadayalan, A D Timmis
}

See end of article for authors' affiliations

\section{Correspondence to:}

Dr A Varnava, London Chest Hospital, Bonner Road, London E2 9JX, UK; avarnava@sghms.ac.uk

Accepted

28 November 2001

\begin{abstract}
Background: Early discharge after myocardial infarction is safe and feasible. Factors that delay discharge need to be identified in order to improve care and reduce bed occupancy.

Objective: To investigate the potential of the restricted weekend service that operates in most hospitals to delay patient discharge.

Design: Prospective cohort study.

Subjects and setting: 2541 consecutive patients with acute myocardial infarction admitted to the coronary care unit of three local district hospitals over a 12 year period.

Results: Clinical factors affecting the duration of stay were age, sex, and severity of infarction. Thus older patients and women stayed significantly longer, as did patients with enzymatically large infarcts. Day of week also had an important influence on duration of stay. Discharge occurred most often on a Friday $(p=0.006)$ and least often over the weekend $(p=0.0001)$. Patients were preferentially discharged on a Friday if the length of stay was more than 72 hours. Thus patients admitted on a Sunday or Monday were usually discharged the following Friday, corresponding to a median duration of stay of five or four days, respectively. For patients admitted on Tuesday to Saturday, weekend discharge was avoided and the median duration of stay was six to eight days.

Conclusions: For patients with acute myocardial infarction, discharge decisions were influenced appropriately by clinical indicators of risk, but inappropriately by the day of the week. Thus weekend discharge was generally avoided, leading to variations in length of stay that were largely determined by the day of the week on which admission occurred rather than clinical need.
\end{abstract}

M any studies have shown the feasibility and safety of discharging patients with acute myocardial infarction as early as 72 hours after hospital admission. ${ }^{1-3}$ The cost effectiveness of early discharge has also been confirmed, ${ }^{4}$ an important consideration when health costs are escalating and bed availability is restricted. Factors that delay discharge therefore not only increase hospital stay, but may also reflect expensive inefficiencies in the health care system if they are unrelated to clinical need.

One factor that has received little consideration is the restricted weekend service offered by most hospitals, with emergency management taking precedence over routine care. This provides adequately for patient safety but whether it interferes with discharge planning and prolongs the duration of hospital stay unnecessarily is not known.

In the present study, we prospectively assessed factors affecting the discharge of patients with acute myocardial infarction, with particular attention to the effects of restricted weekend service on the duration of stay.

\section{METHODS}

\section{Study population}

The study population consisted of 2541 consecutive patients with acute myocardial infarction admitted to the coronary care units of three local district hospitals-Newham General Hospital, The Royal London Hospital, Whitechapel, and King George's Hospital, Ilford-over a 12 year period from 1 January 1988 to 31 December 1999. Of this population, 300 were excluded from further analysis as they had died during the hospital admission. The diagnosis of acute myocardial infarction was based on any two of the following three criteria: cardiac chest pain lasting at least 30 minutes; ECG changes of myocardial infarction with $\geqslant 0.2 \mathrm{mV}$ ST elevation in two or more contiguous chest leads; a diagnostic rise in creatinine kinase to $\geqslant 400 \mathrm{IU} / \mathrm{l}$ (upper limit of reference range, $200 \mathrm{IU} / \mathrm{l}$ ).

\section{Data collection}

Baseline data, including the date and time of onset of chest pain, and details of treatment on admission were entered onto a purpose designed database. Racial group was recorded in all patients by direct inquiry, South Asian being defined as Indian, Pakistani, or Bangladeshi. A diagnosis of diabetes was recorded if the patient required insulin, oral hypoglycaemic agents, or dietary sugar restriction. Smoking habit was classified into those who had never smoked, ex-smokers, and current smokers.

\section{Statistical analysis}

Geometric mean (back transformed mean log) length of stay was calculated for subjects in different prognostic groups, because of the skewed distribution of the data. Determinants of length of stay were examined using multiple linear regression. Log transformed length of stay was used as the outcome variable. Day of the week, age (categorical: $<55$, 55-65, 65-75, 75+ years), sex, ethnic group, year of admission, smoking, diabetes, hypertension, atrial fibrillation, primary ventricular fibrillation, left ventricular failure, peak creatine kinase, and stroke were used as predictor variables. Subjects who died before discharge were excluded from these discharge analyses.

\section{RESULTS}

The baseline characteristics of all 2541 subjects are shown in table 1 . The median length of stay was 7 days (interquartile range 5-10 days), and 98\% of patients were admitted for at least 72 hours.

\section{Clinical determinants of hospital stay}

Average hospital stay declined progressively during the study period (table 2), although the pattern of hospital discharge 


\begin{tabular}{|lll|}
\hline \multicolumn{3}{l}{$\begin{array}{l}\text { Table } 1 \\
\text { Baseline characteristics of } \\
\text { the study population }\end{array}$} \\
\hline Variable & Number & $\%$ \\
\hline Age (years) & & \\
$<55$ & 607 & 24 \\
$55-65$ & 727 & 29 \\
$65-75$ & 708 & 28 \\
$75+$ & 499 & 19 \\
Smoking status & & \\
Current smoker & 1169 & 46 \\
Ex-smoker & 487 & 19 \\
Never smoked & 839 & 33 \\
Unknown & 46 & 2 \\
Racial group & 1782 & 71 \\
White & 688 & 27 \\
South Asian & 45 & 2 \\
Other & 26 & 1 \\
Unknown & & \\
Diabetes & 567 & 22 \\
Yes & 1957 & 77 \\
No & 17 & 1 \\
Unknown & & \\
\hline & & \\
\hline
\end{tabular}

(according to the day of the week) remained constant throughout. Clinical determinants of stay were age, sex, and severity of infarction. Thus older patients and women stayed longer, as did patients with enzymatically large infarcts complicated by atrial fibrillation, primary ventricular fibrillation, or left ventricular failure.

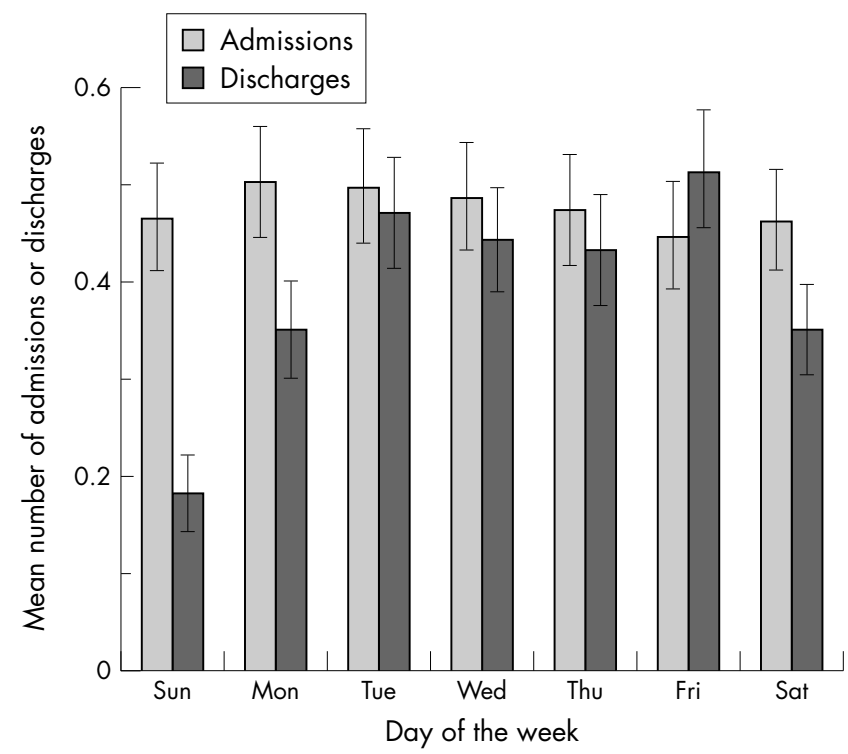

Figure 1 Mean number of admissions and discharges on different days of the week.

\section{Day of week and hospital stay}

Admission rates by day of week were fairly constant $(p=0.16)$, but discharge rates were significantly higher on Fridays $(p=0.003)$ and lower over weekends $(p<0.0001)$ (fig 1). This pattern was similar for each of the three hospitals contributing to the study, and was independent of age group.

\begin{tabular}{|c|c|c|c|c|}
\hline Variable & & $\begin{array}{l}\text { Geometric mean } \\
\text { length of stay } \\
\text { (days) }\end{array}$ & $95 \% \mathrm{Cl}$ & $\begin{array}{l}\text { p Value for } \\
\text { difference } \\
\text { (adjusted) }\end{array}$ \\
\hline Age (years) & $\begin{array}{l}<55 \\
55-65 \\
65-75 \\
75+\end{array}$ & $\begin{array}{l}7.15 \\
7.36 \\
7.75 \\
8.64\end{array}$ & $\begin{array}{l}6.83 \text { to } 7.47 \\
7.07 \text { to } 7.66 \\
7.39 \text { to } 8.12 \\
8.14 \text { to } 9.17\end{array}$ & 0.0001 \\
\hline Sex & $\begin{array}{l}\text { Male } \\
\text { Female }\end{array}$ & $\begin{array}{l}7.40 \\
8.30\end{array}$ & $\begin{array}{l}7.21 \text { to } 7.60 \\
7.90 \text { to } 8.71\end{array}$ & 0.012 \\
\hline Year of admission & $\begin{array}{l}1988-90 \\
1991-93 \\
1994-96 \\
1997-99\end{array}$ & $\begin{array}{r}11.01 \\
7.79 \\
7.12 \\
6.45\end{array}$ & $\begin{array}{l}10.60 \text { to } 11.44 \\
7.48 \text { to } 8.11 \\
6.83 \text { to } 7.42 \\
6.18 \text { to } 6.74\end{array}$ & $<0.0001$ \\
\hline Smoking & $\begin{array}{l}\text { Never } \\
\text { Ex } \\
\text { Current }\end{array}$ & $\begin{array}{l}7.52 \\
7.93 \\
7.54\end{array}$ & $\begin{array}{l}7.22 \text { to } 7.84 \\
7.49 \text { to } 8.40 \\
7.30 \text { to } 7.79\end{array}$ & 0.13 \\
\hline Diabetes & $\begin{array}{l}\text { Yes } \\
\text { No }\end{array}$ & $\begin{array}{l}8.10 \\
7.48\end{array}$ & $\begin{array}{l}7.69 \text { to } 8.53 \\
7.28 \text { to } 7.68\end{array}$ & 0.058 \\
\hline Atrial fibrillation & $\begin{array}{l}\text { Yes } \\
\text { No }\end{array}$ & $\begin{array}{l}9.93 \\
7.39\end{array}$ & $\begin{array}{l}9.16 \text { to } 10.76 \\
7.21 \text { to } 7.57\end{array}$ & 0.0002 \\
\hline Hypertension & $\begin{array}{l}\text { Yes } \\
\text { No }\end{array}$ & $\begin{array}{l}7.80 \\
7.50\end{array}$ & $\begin{array}{l}7.47 \text { to } 8.14 \\
7.29 \text { to } 7.71\end{array}$ & 0.12 \\
\hline Stroke & $\begin{array}{l}\text { Yes } \\
\text { No }\end{array}$ & $\begin{array}{r}12.87 \\
7.57\end{array}$ & $\begin{array}{l}9.02 \text { to } 18.36 \\
7.39 \text { to } 7.75\end{array}$ & $<0.0001$ \\
\hline Ventricular fibrillation & $\begin{array}{l}\text { Yes } \\
\text { No }\end{array}$ & $\begin{array}{l}9.79 \\
7.49\end{array}$ & $\begin{array}{l}8.75 \text { to } 10.95 \\
7.31 \text { to } 7.67\end{array}$ & 0.012 \\
\hline Left ventricular failure & $\begin{array}{l}\text { Yes } \\
\text { No }\end{array}$ & $\begin{array}{l}9.72 \\
6.99\end{array}$ & $\begin{array}{l}9.26 \text { to } 10.21 \\
6.81 \text { to } 7.17\end{array}$ & $<0.0001$ \\
\hline Peak creatinine kinase (IU/I) & $\begin{array}{l}<500 \\
500-1000 \\
1000-1500 \\
1500+\end{array}$ & $\begin{array}{l}7.25 \\
7.03 \\
7.88 \\
8.43\end{array}$ & $\begin{array}{l}6.90 \text { to } 7.60 \\
6.71 \text { to } 7.37 \\
7.57 \text { to } 8.21 \\
7.99 \text { to } 8.88\end{array}$ & 0.012 \\
\hline
\end{tabular}




\begin{tabular}{|c|c|c|}
\hline \multicolumn{3}{|c|}{$\begin{array}{l}\text { Table } 3 \text { Length of stay according to } \\
\text { day of admission }\end{array}$} \\
\hline $\begin{array}{l}\text { Day of } \\
\text { admission }\end{array}$ & $\begin{array}{l}\text { Geometric } \\
\text { mean length } \\
\text { of stay (days) }\end{array}$ & $95 \% \mathrm{Cl}$ \\
\hline Sunday & 7.12 & 6.68 to 7.57 \\
\hline Monday & 7.15 & 6.69 to 7.65 \\
\hline Tuesday & 7.68 & 7.26 to 8.12 \\
\hline Wednesday & 7.56 & 7.11 to 8.03 \\
\hline Thursday & 7.85 & 7.37 to 8.37 \\
\hline Friday & 8.40 & 7.93 to 8.90 \\
\hline Saturday & 7.60 & 7.11 to 8.11 \\
\hline Overall & 7.61 & 7.43 to 7.79 \\
\hline
\end{tabular}

Length of stay (geometric mean with 95\% confidence intervals) (table 3 ) was significantly associated with day of admission $(p=0.004)$, even after adjustment for all other factors $(\mathrm{p}=0.002)$ including comorbidity and complications (fig 2). Patients admitted on a Sunday or Monday had a shorter length of stay than patients admitted on any other week day $(p=0.0006)$, and those admitted on a Friday a longer stay $(\mathrm{p}=0.0009)$.

For patients admitted on Saturday, Sunday, or Monday the greatest number of discharges occurred on the first Friday (days 6, 5, and 4, respectively). For patients admitted on a Thursday or Friday the proportion discharged was highest on the second Friday (days 8 and 7, respectively). For patients admitted on a Tuesday or Wednesday, the proportion discharged was greatest on the following Tuesday (days 7 and 6 , respectively).

\section{DISCUSSION}

This prospective cohort study of patients with acute myocardial infarction has shown that discharge decisions were influenced appropriately by clinical indicators of risk, but inappropriately by the day of the week. Thus weekend discharge was generally avoided, leading to variations in length of stay that were largely determined by the day of the week on which admission occurred rather than by clinical need.

Risk stratification in acute myocardial infarction can help rationalise discharge decisions. ${ }^{56}$ In low risk cases, investigators have confirmed the safety of early discharge, with a decline in the recommended duration of stay in recent years. ${ }^{17}$ Cases with clinical indicators of heightened risk, however, benefit from more prolonged hospital stay. Accordingly, we found that the average length of hospital stay decreased progressively over the study period, although patients at higher risk by virtue of age, enzymatic infarct size, or complications were generally retained longer in hospital. In this respect, discharge planning was evidence based and clearly reflected clinical need.

The lower rate of discharge at weekends, however, cannot be explained by clinical need. It occurred independently of all clinical indicators of risk, including age, indicating that difficulty providing social support for elderly patients was not a factor. The only plausible explanation is the restricted hospital service at weekends, ${ }^{8}$ when medical staff are often unavailable to make or implement discharge decisions. Indeed, a recent study has shown that for some medical conditions patients admitted on a weekend are more likely to die than those admitted on a weekday. ${ }^{9}$ Reluctance to discharge patients at weekends, coupled with the need, on clinical grounds, to achieve at least 72 hours of hospital admission, resulted in two different patterns of discharge. For patients admitted on a Sunday or Monday, discharge occurred most often on the following Friday, ensuring early discharge after four to five days while avoiding the weekend. In contrast, most patients admitted on Tuesday through to Saturday were kept in hospital over the weekend, with Monday review further delaying discharge until Tuesday or beyond, usually after six to eight days. Thus patients were preferably discharged on Friday, avoiding the weekend, if the length of stay was at least 72 hours. If the stay was less than 72 hours before the first Friday following admission, then patients were kept in over the weekend to be discharged on days 6 to 8 . This apparent
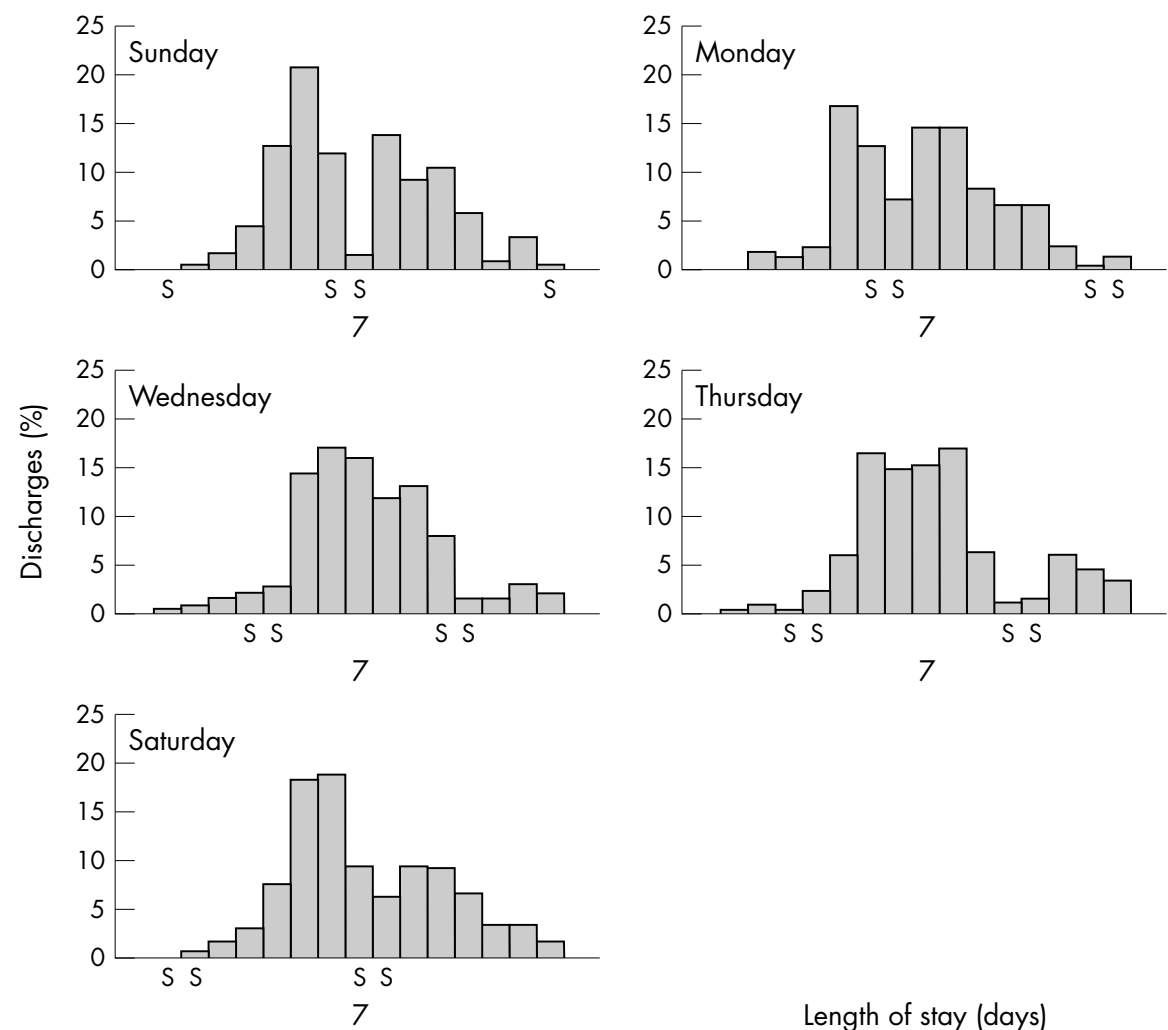
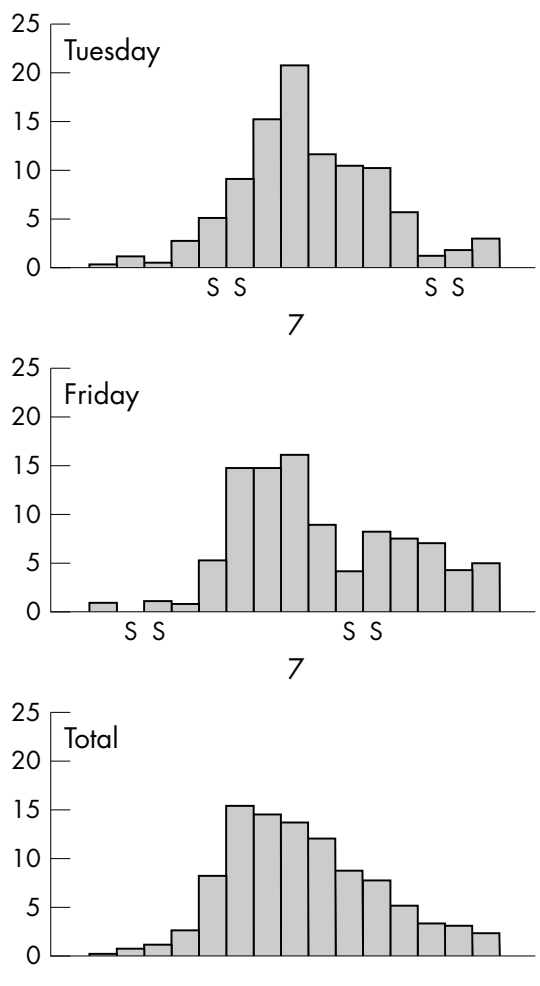

7

Figure 2 Length of hospital stay following myocardial infarction by day of admission. 
preference for a Friday or Tuesday discharge was probably attributable to the physicians' preference for discharging patients either before or after the weekend (with Monday discharge being delayed to Tuesday because of the need for a post-weekend review). The net effect, therefore, was to prolong hospital stay by up to three days in many patients. The same pattern was reproduced in each of three hospitals and, if the results are generalisable to other hospitals and other medical disorders, the scale of the problem in terms of bed occupancy and health care costs must be considerable.

The inefficiencies that result from restricted weekend service extend beyond direct effects on discharge decisions. Thus unavailability of cardiac investigations, including stress testing and cardiac catheterisation, may also contribute by delaying essential work up. Expediting the clinical assessment of these patients, either immediately on resumption of routine services or by making certain services available seven days a week, would address this issue.

\section{Conclusions}

Restricted weekend service prolongs the hospital stay of many patients with acute myocardial infarction unnecessarily. Formal discharge planning based on risk stratification early after admission ${ }^{2}$ could largely eliminate this inefficient practice by prospectively identifying the day of discharge, as defined by clinical need. In this way discharge at weekends could be planned during the working week, reducing average hospital stay, with potentially beneficial consequences for health care costs.

\section{Authors' affiliations}

A M Varnava, A D Timmis, Department of Cardiology, London Chest Hospital, Bonner Road, London E2, UK

J E C Sedgwick, Department of Public Health Sciences, Guy's, King's and St Thomas' School of Medicine, London SE I, UK

A Deaner, Department of Cardiology, King George's Hospital, llford, Essex, UK

K Raniadayalan, Department of Cardiology, Newham General Hospital, Glen Road, London E13, UK

\section{REFERENCES}

1 Topol EJ, Burek K, O’Neill WW, et al. A randomized controlled trial of hospital discharge three days after myocardial infarction in the era of reperfusion. N Engl J Med 1988;318:1083-8.

2 Mark DB, Sigmon K, Topol EJ, et al. Identification of acute myocardial infarction patients suitable for early hospital discharge after aggressive interventional therapy. Results from the thrombolysis and angioplasty in acute myocardial infarction registry. Circulation 1991;83:1186-93.

3 Newby LK, Califf RM, Guerci A, et al. Early discharge in the thrombolytic era: an analysis of criteria for uncomplicated infarction from the global utilization of streptokinase and t-PA for occluded coronary the global utilization of streptokinase and t-PA for occluded corc

4 Newby LK, Eisenstein EL, Califf RM, et al. Cost effectiveness of early discharge after uncomplicated acute myocardial infarction. N Engl J Med

5 Madsen EB, Hougaard P, Gilpin E, et al. The length of hospitalization after acute myocardial infarction determined by risk calculation. Circulation 1983:68:9-16

6 Jain A, Myers GH, Sapin PM, et al. Comparison of symptom-limited and low level exercise tolerance tests early after myocardial infarction. J Am Coll Cardiol 1993;22:1816-20.

7 Antman EM, Kuntz KM. The length of the hospital stay after acute Antman EM, Kuntz KM. The length of the hospital stay afte
myocardial infarction. N Engl J Med 2000;342:808-9.

8 Ottesen MM, Kober L, Jorgensen S, et al. Determinants of delay between symptoms and hospital admission in 5978 patients with acute myocardial infarction. Eur Heart J 1996;1 17:429-37

9 Bell CM, Redelmeier DA. Mortality among patients admitted to hospitals on weekends as compared with weekdays. N Engl J Med 2001;345:663-8.

\section{IMAGES IN CARDIOLOGY}

\section{A case of spontaneous closure of coronary artery fistula with familial hypercholesterolaemia}
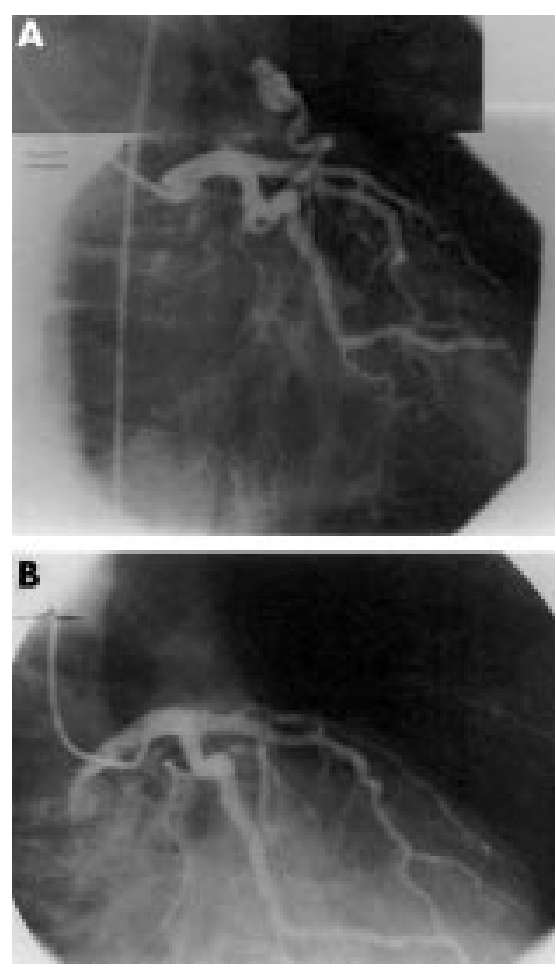

43 year old Japanese man was referred for investigation of occasional chest pain. He was a $\triangle$ heavy smoker and was diagnosed as having familial hypercholesterolaemia. No heart murmur was heard. Chest $x$ ray, electrocardiography, and two dimensional echocardiography showed no abnormal findings. Coronary angiography showed normal left and right coronary arteries and a coronary artery fistula between the left anterior descending artery and main pulmonary artery (panel A). Right catheterisation showed normal intracardiac pressures, and there was no increase in oxygen saturation in the pulmonary artery. Other examinations revealed no ischaemia.

At 51 years old the patient was diagnosed as having hypertension. Then, at 53 years of age, he was re-investigated before undergoing surgery for a right common iliac arterial aneurysm. Interestingly, repeat coronary angiography showed spontaneous closure of the previous coronary artery fistula (panel B). The right coronary artery had peripheral stenosis but other sites were not stenotic.

Spontaneous closure of a coronary artery fistula is rare. It has been estimated to occur in $1 \%$ of all reported cases of coronary artery fistulae. Eleven cases have been previously reported; eight cases were under 15 years old and only three cases were adult. The mechanism of spontaneous closure is unclear. Previous reports suggested atherosclerosis, embolism, and vasospasm may be involved. Our patient had familial hypercholesterolaemia, hypertension, and smoked. Thus, spontaneous closure of the fistula may have been caused by an atheromatous plaque.

T Iwaki

M Shimizu

H Mabuchi

t.iwaki@c7.ezweb.ne.jp 